\title{
Authentic Approaches to Music Education with Technology
}

\author{
Dr Jonathan Savage \\ Reader in Education, \\ Faculty of Education \\ Manchester Metropolitan University \\ j.savage@mmu.ac.uk
}

\section{Biography}

I have always had an interest in music technology. Right from the early days of an Atari ST in the mid 1980s, I have been fascinated by what music technology can do for the processes of musical performance and composition. Although my own musical training was fairly conventional, when I started teaching in a school for myself I quickly realized that technology could provide an alternative 'way in' to music making and I sought to integrate various technologies within my teaching. I also began studying for a doctorate that reflected on the uses of technology that experienced composers were making in an electro-acoustic musical environment. I drew on my observations of, and conversations with, these composers and designed a range of curriculum projects that built upon them. Since then, I have researched how music education can be developed through the use of technology and sought to inspire others to do the same. The challenges and joys of working with young teachers each year are inspiring. However, one thing is crucial to me. Music technologies provide a range of tools; they are means to an end; they are not 'the' end in and of themselves.

\section{Introduction}

Robert Benchley, the famous American columnist, once quipped that 'there are two kinds of people in the world: those who divide the world into two kinds of people, and those who don't'. I was reminded of the quote when approached to write this chapter that addresses, amongst other questions, whether 'music technology' should be taught as an independent subject or should it be integrated across the music curriculum? It does seem to be the case that human beings are prone to like to categorise things; music education is no exception. But, as we will discover, this can lead to many unhelpful, although perhaps unintended, consequences. So, this is an important question but, in many senses and in the United Kingdom's schools and colleges at least, it has been answered in recent years through educational policy and resulting curriculum frameworks. However, this does not mean that the questions are not worthy of further consideration.

Given this mix of experiences, this paper will begin with an examination of the current curriculum framework in the United Kingdom and analyse some of the consequences of this separation between Music and Music Technology. Following this, I will present two alternative visions of musicianship, drawn the work of two 
writers, and argue that a more coherent approach to the development of music technology skills within a music teacher's pedagogy is urgently needed.

\section{Music Education with Technology in the United Kingdom}

The National Curriculum for England still includes Music as a subject. This means that it should be taught in all state-maintained primary and secondary schools. The National Curriculum is still structured around Key Stages and the new, revised, National Curriculum will be implemented in schools in September 2014 (DfE 2013).

For the last sixteen years, students have been able to study for a separate Advanced Level (A Level) qualification in music technology; more recently, during the early 2000s, vocational qualifications in Music with a significant, if not entire, course content devoted to music technology, recording, production and other technologicallymediated musical activities have been available to students from the age of 14 onwards. Alongside these specialist courses, references to music technology and its use have continued to appear in National Curriculum Programmes of Study in various forms. Students have also been able to study music in more traditional qualifications such as General Certificate of Secondary Education (GCSE) and A Level Music courses.

The fate of music technology within the revision process surrounding the National Curriculum has been mixed. From September 2014, having been present in the previous Programmes of Study, it is now entirely absent from the Key Stage 2 programme of study (for children aged between 7 to 11 years of age). At Key Stage 3 (for children aged between 11 to 14 years), the National Curriculum makes mention of music technology in one sentence: 'they [students] should use technologies appropriately and appreciate and understand a wide range of musical contexts and styles (DfE 2013).

The second key element of music education is the General Certificate of Secondary Education (GCSE), the principle mechanism for the assessment of students at the age of 16. Despite a reprioritisation of subjects, that has meant that Music has been placed in the lowest tier (and will be ignored by many students, parents and schools), students may still have access to a GCSE in Music course in many schools. But, as I will show below, numbers of students taking this examination have fallen by $11 \%$ over three years and the trend is only going to continue on a downwards spiral.

At Key Stage 5 ('Advanced Level' for students aged between 16-18) qualifications have remained in Music and, as a separate qualification, in Music Technology. These qualifications are accompanied by a range of vocational qualifications in Music such as the BTec First (for students in the Key Stage 4 age range) and BTec National (for students at Key Stage 5). Both these BTec qualifications contain a significant amount of music technology-related content. 
What is quickly apparent from a cursory overview of the curriculum and qualification frameworks within the United Kingdom is that students' experience of music technology begins as part of broader music curriculum experience within the school but quickly becomes specialised around the age of fourteen into discrete qualifications that focus, to a greater or lesser extent, on the specialist skills associated with music technology.

An analysis of the number of students taking these examinations is informative. Using figures drawn from Government sources (Cambridge Associates 2013a, 2012a, 2011a) it is clear that the number of students studying for an A level in Music and an A level in Music Technology have fallen by around 35\% over the last three years. Whilst the gender balance in relation to A Level Music slightly favours boys (16\% more boys than girls studied for this examination in 2012), the differences in terms of gender within the A Level Music Technology intake are stark. Between 2010 and 2012, for example, $85 \%$ of entrants for this examination were male.

In respect of the 'vocational' curriculum offered through qualifications such as the BTec First and BTec National examinations, a similarly marked difference in gender is noted (Edexcel 2012 \& 2013). Across the entire portfolio of examinations (i.e. in every subject) offered by Edexcel (the awarding body), male students favour female students by $52 \%$ to $48 \%$. However, within the Music course that, as stated, have a core element of music technology within them, the gender imbalance is significant. Over the last three years, within the Level 2 BTec First male students account for around $63 \%$ of the total student entries; at Level 3 (BTec National) they account for $80 \%$ of the total student entries.

Against this backdrop, the GCSE Music examination has been taken by around 11\% fewer students in 2012 compared to 2010 (Cambridge Associates 2013b, 2012b \& 2011b). The gender imbalance has narrowed from around a 10\% gap (with boys outnumbering girls) in 2010 to a 3\% difference in favour of the boys in 2013.

I have dwelt on these figures for a number of reasons. Firstly, and obviously, the separation of the study of music technology from the study of music in the United Kingdom's curriculum and examination framework has created a significant gender imbalance. Whilst the number of boys studying a formal qualification in music or music technology always outnumbers the number of girls studying for the same qualification, the more music technology content that is included within the examination itself results in the gap between male and female students widening (at its largest to a massive $80 \%$ difference with the Level 3 BTec qualifications).

Secondly, the decline in students taking GCSE and A Level examinations has been marked, whilst during the same period of time the total number of students taking vocational qualifications such as the BTec courses referred to here has increased by around 22\% since 2012 to 2013 . What are perceived as academic qualifications on one hand have diminished, whilst those relating more closely to technological skills, popular musical styles and perceived employability have prospered. I make no value 
judgements here, but the change in fortunes is stark. However, this is set to change significantly from September 2014 when certain qualifications of this type are downgraded by the Government and will not count in the assessment of a school's performance tables. This will result in large numbers of schools opting out of these more vocational course and pushing students into the standard GCSE programmes that they offer.

On balance, these changes reinforce the folly of categorising musicians and musical activity by type or technology. Within the United Kingdom, the move in the 1990s to distinguish music without technology (in a general sense) from music with technology has resulted in such a highly unhelpful, gendered and rigid delineation of musical content, activity and technologically-mediated practice to such an extent that it is difficult to see any way in which this could be reversed. This has had a major impact on the way in which individual students saw their musical skills. Many of the students are the ones that are training to be teachers today.

To help explore the issues here in a little more detail, I would like to shift my focus to the work and practice of an individual musician. In what follows, I will present two alternative 'visions' of a musician who uses technology. The first of these is Hugill's vision of the 'digital musician' (Hugill 2008).

\section{Challenging the notion of the Digital Musician}

In his book The Digital Musician, Hugill suggests digital musicians are a discrete class of musician who exhibit certain characteristics that separate them from other musicians (who, he acknowledges) may make use of digital technologies on odd occasions within their work). Hugill acknowledges that the classification of musicians into 'types' is bound to be problematic. Yet this does not stop him embarking on a stringent approach to the classification of musicians by various labels including musical 'dimensions' or 'resource'.

For instance, he starts with those musicians who work in established traditions such as classical or folk music whose principal preoccupation, he argues, is 'pitch'. These musicians:

... generally play an acoustic instrument as their main practice, and they travel a prescribed career path that involves the gradual evolution of technique and musicianship. The criteria for recognising virtuosity are clearly established, and there is broad agreement among listeners about the level that an individual musician has attained. (ibid, p.3)

Secondly, he cites 'rhythm' or 'beat' as being a primary starting point for popular musicians. These musicians:

... tend to show a relative lack of interest in pitch when compared to the first type, although of course they do not ignore it completely. Bands without some sort of percussion section are rare, and, when they do appear, the instruments often 
emphasise rhythmic content in order to compensate. (ibid)

A third type of musician starts with timbre. These musicians, he suggests, are:

... harder to pin down, for the simple reason that many timbre-focused artists do not consider themselves to be musicians at all, or do not use the word 'music' to describe what they produce. Into this category can be placed the majority of those working in electronic and electro-acoustic music, but also sonic art, sound-art, sound design and various forms of radiophonic and speech-based works. By dealing with sounds rather than notes, these musicians have changed the nature of music itself, raising questions about what is 'musical'. (ibid, p.4).

Digital musicians, for Hugill, are not defined by their use of technology per se. A classical pianist giving a recital on a digital piano is not a digital musician; nor is a composer using a music notation software to compose a string quartet. Hugill's definition of a digital musician is as follows:

A digital musician is one who has embraced the possibilities opened up by new technologies, in particular the potential of the computer for exploring, organising and processing sound, and the development of numerous other digital tools and devices which enable musical invention and discovery. This is a starting point for creativity of a kind that differs from previously established musical practice in certain respects, and requires a different attitude of mind. These musicians will be concerned not only with how to do what they do, or what to do, but also with why to make music. A digital musician, therefore, has a certain curiosity, a questioning and critical engagement that goes with the territory. (ibid)

Furthermore, Hugill goes on to specifically distinguish what makes a 'digital musician' different from other musicians. The skills that a digital musician requires, he argues, are as follows:

- Aural awareness (an ability to hear and listen both widely and accurately, linked to an understanding of how sound behaves in space and time);

- Cultural knowledge (an understanding of one's place within a local and global culture coupled with an ability to make critical judgements and a knowledge of recent cultural developments);

- Musical abilities (the ability to make music in various ways performance, improvisation, composition, etc. using the new technologies);

- Technical skills (skill in recording, producing, processing, manipulating and disseminating music and sound using digital technologies). (ibid, p.5)

The notion of a digital musician is a flawed one. It makes little if any sense in my view. It is about as useless as defining a musician as being principally concerned with pitch, rhythm or timbre. Classifications of this type are worse than simplistic and reductionist; they are dangerous and divisive and, as I have described above, have resulted in an unhelpful demarcation in terms of the curriculum within the United Kingdom. They have also led to a crisis in confidence in music teachers' perceived skills (of which more below). 
In contrast to Hugill's characterisation of the digital musician, I would like to explore an alternative model drawn from the work of one of the most interesting electroacoustic composers that I have had the privilege of working with - John Bowers.

\section{The Improvising Musicians}

Bowers' Improvising Machines (Bowers 2003) explores the improvisation of electroacoustic music from various standpoints, including its musicological, aesthetic, practical and technical-design dimensions. Within it, detailed ethnographic descriptions of the author's own musical performances over a period of a number of years at different concerts across Europe are described, and the various pieces of hardware and software through which these were facilitated are analysed. For anyone with an interest in electro-acoustic music, musical improvisation, the human-design interface and the wider adoption of digital technologies it is a fascinating account.

Bowers presents an argument that electroacoustic music is an indigenous 'machine music'. He explores his own experience as an improviser in this idiom, giving special attention to observable variations in the forms of technical interactivity, social interaction and musical material which existed across the various musical performances that he gave with fellow performers. It is towards the end of this chapter (ibid, pp.42-51) that he identifies four issues that inform his writing in later chapters (notably the exploration and development of a technical design aesthetic in Chapter 3 ), but are of particular interest me here in relation to our discussion of how music education with technology could be more broadly defined, integrated and promoted within the curriculum and examination frameworks.

\section{Contingent Practical Configurations}

The music has arisen in relation to these contingencies in such a way that, from an ethnographic point of view, it should not be analytically separated from them. (ibid, p.43)

Bowers defines 'contingent practical configurations' as the technologies used, musical materials and forms explored, performance practices employed, and the specific setting and occasion of, as well as the understanding generated from, musical improvisation with technology. Contingencies of this type are 'topicalised' within the performance itself. They are integral to it and shape the resulting musical statements, interactions and expressions. Improvised musical conduct of the sort Bowers described is a space in which contingencies are worked through in real time and in public. The specific contingency of a technology-rich musical improvisational conduct is embodied in the relationship between human beings and their machines. You cannot have one without the other. Specifically, 'it is in our abilities to work with and display a manifold of human-machine relationships that our accountability of 
performance should reside' (ibid, p.44).

\section{Variable Sociality}

For Bowers, variable sociality is the different social interactions and relationships that are worked out through musical performance:

The sociality of musical production is an important feature of improvised electro-acoustic music. Publicly displaying the different ways in which performers can position themselves with respect to each other and the different ways in which technologies can be deployed to enforce, negate, mesh with, disrupt, or otherwise relate to the local socialities of performance could [again] become the whole point of doing it. (ibid, p.45)

As with any musical practice, within 'machine music' the social, interactional relationships that Bowers and his fellow musicians enjoyed varied over time. There was a deliberate playfulness. Different alternatives were experimented with, variably and often interchangeably, within the course of a specific musical performance. Social norms could be disrupted at a particular point, perhaps due to technical issues (perhaps the cables were not long enough or the monitoring was lop-sided) or other factors (the audience began to leave or the music was too loud and complaints were received from others in the locality). The social dimensions of musical production are highly important. They need to be understood and explored as an integral part of the aesthetic, not as a separate issue.

\section{Variable Engagement and Interactivity}

Just as performers can variably relate to each other, they can variably engage with the technologies and instruments before them. (ibid, p.45)

Linked to the above, Bower's concept of variable engagement and interactivity facilitates a consideration of the different and varying relations that performers have with their instruments and technologies. In particular, he identifies a number of different patterns of engagement for the musical performer and for the listener.

His twelve-hour musical performance in Ipswich (at which audience members were given a free can of baked beans in return for their attendance!) utilised a range of mechanised musical production technologies that, at particular points, automatically set new parameters for musical statements or even drew on new source materials from the performer's laptop computers. The pattern of engagement from the performer's point of view was one of initiation, delegation, supervision and intervention. This process meant that it was not always necessary for one, or both, of the musical performers to be physically present within the space for the whole of the twelve hours.

Other more conventional forms of musical production within Bower's performance 
events utilised conventional instruments that required some kind of human incitement to action (striking something, manually triggering a sample, etc). The pattern of engagement here would be one of physical excitement/incitement and manipulation.

Different forms of engagement have different phenomenologies associated with them. How one listens, hears or responds intellectually or is physically moved all effect and affect one's engagement and interaction with sound and its means of production.

\section{Musical Materials}

To construct workable and intelligible performance environments, I have made various distinctions between these musical materials in terms of their real-world sources, the media by which they are conveyed, the manipulability of those media, the kinds of gestures and devices which are used to realise those manipulations. From time to time, all of those features are seen to be bound up with identifiable forms of social organisation between coperformers, and those forms of interaction have musical-formal aspects to boot. I have tried to reveal these interconnections through ethnographic description of the performance situation. (ibid, p.48)

Bowers' sophisticated organisation of musical materials draws on a range of existing methodological structures for electroacoustic composition. Whilst he is at pains to emphasise the differences here, his account is illuminating when placed alongside his analysis of Schaeffer's acousmatic composition (and allied practices), Emmerson's distinction between aural and mimetic discourse, and Smalley's spectromorphological categorisations. These all provide a frame for dialogue and discussion about the sounds that Bowers and his co-performers produced during their improvisations and, importantly for us, about how they reflected on and justified the musical 'product' that resulted at the various concerts.

Central to this discussion (ibid, pp.48-50) is the question of how an overall musical structure of 'syntax' can emerge from an improvised performance practice. Drawing directly on Emmerson's work on musical syntax (Emmerson 1986), Bowers writes that:

Improvised forms are naturally immanent, ad hoc-ed moment-by-moment on the basis of what has gone before and projecting opportunities for what might come following. In the language I hinted at above, multiple threads of significance may link up several of the elements in play. There may still be singularities and other 'unattached' offerings. The threads may be thin or may be densely interwoven (steady with the metaphor now!). We may have a sense of 'a piece' or a collection of 'moments' or some point in between. These are some of the immanent forms, of abstracted syntax, one can hear generated by electro-acoustic improvisors. (ibid, p.50)

\section{Authentic Music Technology within Music Education}


Improvising Machines presents an illuminating narrative about the processes and products of his improvisational conduct within the context of electroacoustic music. It contains a blend of musicological features, technical considerations and reflective comments, underpinned throughout by a rigorous approach to ethnographic and critical analysis. What can it teach us music education and how it can be enriched through the use of music technology in an authentic way?

\section{All music education takes place within a rich context of contingent practical elements.}

The contingent practical context of music education is fundamental and integral to his process of creating music with technology. It is only through a strong commitment to exploring the intricate relationships that develop that a true (or at least a defensible) understanding of what music education really is can be created.

This raises a number of pertinent questions. To what extent are we able to map out the contingent practical elements that are at work within a particular context or process of musical instruction? The type and location of these elements might be diverse, extending from the classroom where learning might be initiated, to the students' home environment where it continued and developed, from conversations with their friends at school to conversations they have online with others about their work; they may include formal elements such as the unit of work within which the musical learning is contextualised, to informal elements such as the album of music that the student listened to yesterday. They will undoubtedly include the quality of relationship that the student has both with their teacher, and their peers, their instrumental teacher or other admired role models. They will also include a whole range of digital technologies.

Understanding these elements is important if we are to truly understand and know how that student's musical learning has developed. Only by developing a rich understanding of the broad context within which that student's work has been produced then can you begin to understand why they have made their particular musical choices. This understanding is not helped by simplistic and reductionist categorisations of the type presented within the concept of the 'digital musician'. These only serve to atomise our understanding and prevent us considering in appropriate detail the real essence of what it means to be a musician and a music educator.

\section{Music education always takes place within a rich technological context}

Technologies are integral to all music making, digital or otherwise. I would argue, philosophically, that there is not much difference between the development of the sustain pedal on the pianoforte in the nineteenth century and the latest Boss guitar effect pedal in 2014. Technologies of any type can help enforce the social order, or 
they can negate it; they can facilitate a meshing of ideas and responses, or they helpfully or unhelpfully disrupt them.

The rich technological context of music education extends beyond our choice of instruments and their use in educational settings. The broad array of technology that mediates our students' lives implicate, fundamentally, their engagement with us, as teachers, and music more broadly. One can not escape this, and it is ridiculous to imagine that one can.

\section{Working productively with technologies: initiation, delegation, supervision and intervention}

As I have discussed, making music with any technology, digital or otherwise, is a complex business. It builds on numerous contingent practical elements and configurations that are mediated through a process of variable sociality. It demands that a student is able to diagnose and work within a range of approaches for musical engagement and interactivity in an integrated and holistic way. Trying to disassemble skills, concepts or processes as technological or non-technological is nonsensical. As teachers, it is vital that we understanding these processes; policy makes to develop examination frameworks that facilitate them in an integrated way.

Different technologies demand different approaches. We need to encourage our students to be flexible, to embrace and respond, intuitively and fluently, to the emerging streams of sound that these technologies produce. As teachers, we can initiate something. We can start our students off in a direction. But following an initiation, there is a delegation. For effective musical learning to take place, we need to allow our students to take ownership of their creative ideas. They need space and autonomy, time to explore, to experiment, to work with their machines and obtain outcomes that are of value to them. Delegation might involve handing over significant control to a technology, for a time, to see what emerges. The key here is to consider the human endeavour in equal measure to the technological input. It is the student who will add and express value to a technological utterance.

If students are not to continue their work indefinitely, there will come a time when the teacher has to exercise a legitimate supervisory role. Perhaps the time is up for that piece of work, a new direction needs to be taken, or the deadline for submission is near. With supervision comes intervention. Intervention might mean a day of reckoning, a formal assessment or examination. However, it could just mean a moment of reckoning or accountability, a pointing in a new direction - a tack as it were - before the students are off again.

Initiation, delegation, supervision and intervention; here is just one potential approach to music education that is in tune with the ways of working with digital technologies inspired by Bowers' Improvising Machines. 


\section{Conclusion: It's all about the music, not the technology}

Music is not a universal language, but within the specific musical utterances of a particular genre or style one can begin to recognise gestures, shapes, sentences that carry meaning. The use of all technologies, digital or otherwise, need to firmly contextualised within music itself. Technologies are authenticated within the context within which it they are used. For teachers, the key is to find a way to integrate music technology into musical activities, games, curricula or conversations with their students in a way that facilitates their students' creativity and engagement with music itself.

Within the United Kingdom, for the foreseeable future, teachers and their students will work within examination and curriculum frameworks that are seeking to divorce musical skills and processes from those categorised as being concerned with 'music technology'. This is a system that prioritises certain forms of knowledge in a simplistic and unhelpful way, e.g. the rewards of studying for an A Level in 'Music', as opposed to 'Music Technology' are more favourable (e.g. in accessing a course of higher education). As we have seen, it also creates artificial and unhelpful barriers in terms of the gendered discourse surrounding music itself. These are very difficult for individual teachers and students to overcome.

However, the study of music and the provision of music education within the context of an individual teacher's work with their students is a location where it may be possible to begin to chip away at some of these barriers. Teachers have a responsibility not to buy into the narrative that music technology is only for some students, perhaps those who cannot access music in the 'proper' way or who are male! They need to realise that the skillsets that they need to implement a broad and appropriate range of music technology within their work is their own responsibility, and not something that should be hived off to a technician or support staff. Most importantly, their conceptual models for music education and how it is organised must be built upon an understanding of an authentic musicianship that embraces technology, of any shape and form, and sees it as integral to musical expression. Music technology is too important to be categorised as being solely within the domain of the 'digital musician' and left at the doorstep in the experiences of so many others. Artificial categorisations only divide; what music education needs to develop first and foremost are students with a rich and authentic music expression regardless of the tools they choose to use.

\section{References}

Bowers, J. (2003), 'Improvising Machines'. http://www.ariada.uea.ac.uk/ariadatexts/ ariada4/ [last accessed 24/1/14].

Cambridge Associates (2013a) 'Uptake of A Level Subjects 2012: Statistics report 
series No. 55'. http://www.cambridgeassessment.org.uk/Images/150182-uptake-ofgce-a-level-subjects-2012.pdf [last accessed 27/1/14].

Cambridge Associates (2013b) 'Uptake of GCSE Subjects 2012: Statistics report series No. 57'. http://www.cambridgeassessment.org.uk/Images/150205-uptake-ofgcse-subjects-2012.pdf [last accessed 27/1/14].

Cambridge Associates (2012a) 'Uptake of A Level Subjects 2011: Statistics report series No. 42'. http://www.cambridgeassessment.org.uk/Images/109931-uptake-ofgce-a-level-subjects-2011.pdf [last accessed 27/1/14].

Cambridge Associates (2012b) 'Uptake of GCSE Subjects 2011: Statistics report series No. 44'. http://www.cambridgeassessment.org.uk/Images/109933-uptake-ofgcse-subjects-2011.pdf [last accessed 27/1/14].

Cambridge Associates (2011a) 'Uptake of A Level Subjects 2010: Statistics report series No. 28 - revised'. http://www.cambridgeassessment.org.uk/Images/109918uptake-of-gce-a-level-subjects-2010.pdf [last accessed 27/1/14].

Cambridge Associates (2011b) 'Uptake of GCSE Subjects 2010: Statistics report series No. 35 - revised'. http://www.cambridgeassessment.org.uk/Images/109925uptake-of-gcse-subjects-2010.pdf [last accessed 27/1/14].

Department for Education (DfE) (2013) National Curriculum in England: Music programmes of study'. https://www.gov.uk/government/publications/nationalcurriculum-in-england-music-programmes-of-study/national-curriculum-in-englandmusic-programmes-of-study [last accessed 27/1/14].

Edexcel (2013) 'BTEC Results Day 2013'. www.edexcel.com/btec/news-andpolicy/.../BTEC results_day 2013.ppt [last accessed 27/1/14].

Edexcel (2012) 'BTEC Results Day 2012'. www.edexcel.com/btec/Documents/ BTEC-Results-Day-2012-External.ppt [last accessed 27/1/14].

Hugill, A. (2008) The Digital Musician. London, Routledge. 